\title{
Political Instability, Gender Discrimination, and Population Growth in Developing Countries
}

\author{
Ulla Lehmijoki \\ University of Helsinki \\ HECER
}

\author{
Tapio Palokangas \\ University of Helsinki \\ HECER and IZA
}

Discussion Paper No. 609:2004

ISBN 952-10-1541-1, ISSN 1459-3696

November 1, 2004

\begin{abstract}
This paper introduces gender discrimination and population growth into a model of political economy. It is assumed that households are family dynasties and the government keeps up the army for the case of political instability in the country. It is shown that there are economic limits to conscription from young men. Therefore, to ensure the sufficient supply of the men in the conscription age, the government boosts population growth though hampering the participation of women in production. Some empirical evidence on the interdependence of political instability and population growth is provided.
\end{abstract}

Journal of Economic Literature: O41, J13, J16

Keywords: population growth, discrimination, political instability

Addresses of Authors: Ulla Lehmijoki, Department of Economics, P.O. Box 17 (Arkadiankatu 7), FIN-00014 University of Helsinki, Finland (email: Ulla.Lehmijoki@helsinki.fi) - Tapio Palokangas, Department of Economics, P.O. Box 17 (Arkadiankatu 7), FIN-00014 University of Helsinki, Finland. Phone (email: Tapio.Palokangas@helsinki.fi) 


\section{Introduction}

Why do politically unstable economies generate high population growth rates and sideline women from productive work? In this paper, we consider this question in a model where the government maintains internal stability by the army but attempts at the same time to be re-elected.

The rulers have always collected armies to hedge against internal or external risks. In particular, they have been interested in the security of their citizens but also their own interests to stay in power. There are two ways of expanding the military. In the short run, conscriptions can be increased, but this inevitably harms private agents at an increasing rate. In the long run, the government can also widen the demographic base for the army.

Even if the risk for open war seems to be decreasing in developed countries, many less developed countries have experienced a continuous risk for riots and civil wars. The number of annual armed conflicts steadily increased from less than twenty in 1950 to almost fifty in 1991 but decreased again from 1991 to 2000 (Eriksson and Wallensteen 2004). ${ }^{1}$ On the other hand, the average demographic growth was over $2.1 \%$ in less developed countries during period 1950-2000. Hence, the population in these countries has almost tripled (United Nations 2003). Could high population growth and political instability be interrelated? Do governments promote population growth?

In the literature of political instability, several reasons has been suggested for this instability. In the well-known article of Easterly and Levine (1997), ethnic diversity encourages poor policy, political instability and poor economic performance. According to Olsson (2004), abundant natural resources such as diamonds can be the source of political unrest. Henderson and Singer (2000) suggest that "semi-democracy" - in the absence of plain oppression or legitimate channels for dispute resolution - causes crises.

In their models of civil wars, Grossman (1995), Azam (1995), and Collier and Hoeffler (1998) consider a rebel who, facing the costs and rewards of the war and the probability of a victory, either behaves peacefully or embarks on a civil war. Grossman (1991) examines a general equilibrium model of both the rebel and the ruler, while Grossman and Kim (1995) consider the effect

\footnotetext{
${ }^{1}$ This is so even if during this period the military expenditure still exceeded $4 \%$ in 18 countries only in Africa and Asia (SIPRI 2004).
} 
of differences in defensive and offensive weapons. Azam (2003) discusses the case where the government pays its potential opponent in return for not engaging in a civil war.

In this paper, we consider the incumbent government which tries to stay in power in the presence of political instability - riots, ethnic conflicts or civil wars - which can be prevented by building up armies. In particular, we focus on the long run demographic effects of the government's military capacity. We consider political instability but not an open war. Hence, no war-related deaths are present.

With the risk of foreign intrusion, the absolute size of the military is the relevant deterrent. With the risk of internal conflicts, the government needs a large military relative to the population to keep the society peaceful. We concentrate on the latter case. Because the government faces the risk of being replaced in a peaceful election, it has to keep the conscription rate tolerable. Population growth increases the proportion of younger generation from which the army is recruited. On the basis of a theoretical model, we construct an empirically robust association between population growth and the proportion of military persons out of total population.

The remainder of the paper is organized as follows. In sections 2-4, we establish a theoretical model which explains the link between population growth, gender discrimination and the size of the military. Empirical evidence is given in section 5 .

\section{Production and capital accumulation}

Consider an economy with identical households and one homogeneous good. The households are modelled as dynastic families which contain people of all generations. The representative household has capital $K$ and population $L$. Half of the population is male and the other half female workers. Male and female labor are different inputs in production. The household allocates a proportion $b$ of female workers to child-rearing. Goods $Y$ and children 
$\dot{L} \doteq d L / d t$, where $t$ is time, are therefore produced as follows:

$$
\begin{aligned}
& Y=F(K, L / 2,(1-b) L / 2)=F(k, 1 / 2,(1-b) / 2) L, \\
& F_{1}>0, \quad F_{2}>0, \quad F_{3}>0, \quad F_{11}<0, \quad F_{13}>0, \quad F_{22}<0, \quad F_{33}<0, \\
& \dot{L}=\gamma b L / 2 \quad \text { or } n \doteq \dot{L} / L=\gamma b / 2,
\end{aligned}
$$

where $L / 2$ is male labor, $(1-b) L / 2$ female labor in production, $a L / 2$ female labor in child-rearing, $\gamma$ the constant level of productivity in child-rearing, $n$ the growth rate of population, $F(\cdot)$ a linearly homogenous and strictly concave production function, and the subscript $i \in\{1,2,3\}$ denotes the partial derivative of $F$ with respect to the $i$ the argument from the left.

We consider a developing country where the government does not have proper tax instruments. For this reason, it controls the behaviour of the people through norms and religious rules (e.g. veils, restrictions of movements). We assume that the government discriminates women when they participate in the labor force. This can be modelled as follows. The government sets a fine $\tau$ to female labor in production and distributes the revenue from this evenly among all $L / 2$ men in the economy. We assume that soldiers are directly supported by their families, so that the government does not collect taxes to pay their salaries. Because capital is the only asset in the economy, the household's budget constraint can then be written in terms of capital accumulation as follows:

$$
\dot{K} \doteq d K / d t=Y+h L / 2-c L-\tau(1-b) L / 2,
$$

where $h$ is the subsidy to men and $c L$ total consumption.

Noting (1), we obtain $b=2 n / \gamma$. To make the solution easier, we change the model into per capita terms and define the function

$$
\begin{aligned}
& G(n, k) \doteq \frac{Y}{L}-n k=F\left(k, \frac{1}{2}, \frac{1-b}{2}\right)-n k=F\left(k, \frac{1}{2}, \frac{1}{2}-\frac{n}{\gamma}\right)-n k, \\
& G_{n}=-F_{3} / \gamma-k<0, \quad G_{k}=F_{1}-n, \quad G_{n n}=F_{33} / \gamma^{2}<0 \\
& G_{k k}=F_{11}<0, \quad G_{n k}=-F_{13} / \gamma-1<0, \quad k \doteq K / L
\end{aligned}
$$

where the subscripts $n$ and $k$ denote the partial derivatives with respect to arguments $n$ and $k$, respectively. Noting (4), we can transform the equation (3) into then the form

$$
\dot{k}=Y / L+h / 2-c-\tau(1-b) / 2-n k=G(n, k)+h / 2-c-\tau(1 / 2-n) .
$$




\section{The military and the household}

In standard models of population growth, the representative household derives utility from per capita consumption $c$ and the number of children $n .^{2}$ In this paper, we assume that "children" are directly at the age of conscription without time lags. A model with such a lag would be excessively complicated to obtain analytical results.

In the absence of immigration and mortality, there is one-to-one correspondence between the rate of population growth and the fertility rate. To defend itself against the risk of a conflict or coup the covernment has to collect armies the member of which are supplied by households out of its young men $n L / 2$. Let the conscription rate be $a$. The size of the military is then an $L / 2$, while $(1-a) n L / 2$ young men stay at home. It is uncomfortable for a family to send its young men to military service, because these dislike the inconveniences of the military life and miss their relatives at home. The young men are also unrest of the risk of a conflict even during the peace.

On the basis of the discussion above, the household's utility is a function of consumption per capita, $c$, and young people in the family relative to total labor, $(1-a / 2) n$. We specify the representative household's objective functional in the form

$$
U=\int_{0}^{\infty} \frac{1}{1-\sigma}\left\{c^{1-\sigma}+\theta\left[\left(1-\frac{a}{2}\right) n\right]^{1-\sigma}-1\right\} e^{-\rho t} d t
$$

where $t$ is time, $\sigma \in(0,1) \cup(1, \infty)$ the inverse of the constant intertemporal elasticity of substitution, $\rho>0$ the constant rate of time preference, and the constant $\theta>0$ gives the weight for young people in household preferences.

The household takes the fine $\tau$, the subsidy $h$, the conscription rate $a$ and the fertility rate as given. The household chooses consumption per capita, $c$, and the fertility rate $n$ to maximize its utility (6) given its budget (3). Omitting terms which are constants for the household, we obtain the Hamiltonian corresponding to this maximization as follows:

$$
H=(1-\sigma)^{-1}\left\{c^{1-\sigma}+\theta[(1-a / 2) n]^{1-\sigma}\right\}+\lambda[G(n, k)+h / 2-c-\tau(1 / 2-n)],
$$

\footnotetext{
${ }^{2}$ Cf. Razin and Ben-Zion (1975) and Becker (1981). The number of children is approximately two if the population growth rate $n$ is zero.
} 
where the co-state variable $\lambda$ evolves according to

$$
\dot{\lambda}=\rho \lambda-\partial H / \partial k=\left[\rho-G_{k}(n, k)\right] \lambda .
$$

The first-order conditions corresponding to the household's maximization are

$$
c^{-\sigma}=\lambda, \quad \partial H / \partial n=\theta(1-a / 2)^{1-\sigma} n^{-\sigma}+\lambda\left[G_{n}(n, k)+\tau\right]=0 .
$$

Given the left-hand equation, we can replace $\lambda$ by $c$ as the co-state variable and transform the equation (8) into

$$
\dot{c} / c=-(1 / \sigma) \dot{\lambda} / \lambda=(1 / \sigma)\left[G_{k}(n, k)-\rho\right] .
$$

From (4) and (9) it follows that

$$
\frac{\partial^{2} H}{\partial n \partial k}=c^{-\sigma} G_{n k}<0, \quad \frac{\partial^{2} H}{\partial n \partial c}=-\left(G_{n}+\tau\right) \sigma c^{-\sigma-1}=\theta\left(1-\frac{a}{2}\right)^{1-\sigma} n^{-\sigma} \frac{\sigma}{c}>0 .
$$

Given these inequalities and the second-order condition $\partial^{2} H / \partial n^{2}<0$, the comparative statics of the right-hand equation in (9) yields

$$
n=\tilde{n}(k, c), \quad \frac{\partial \tilde{n}}{\partial k}=-\frac{\partial^{2} H}{\partial n \partial k} / \frac{\partial^{2} H}{\partial n^{2}}<0, \quad \frac{\partial \tilde{n}}{\partial c}=-\frac{\partial^{2} H}{\partial n \partial c} / \frac{\partial^{2} H}{\partial n^{2}}>0 .
$$

In the definition (4) of the function $G$, the first term $F$ is concave but the second term $-n k$ convex in $(n, k)$. This implies that $G$ may be convex in $(n, k)$ and there may exist multiple steady states for the system (5) and (10). ${ }^{3}$ To eliminate this possibility, we restrict the analysis in the neighborhood of the steady state in which the Hamiltonian is concave in $(n, k)$. Noting (11), we obtain that the system (5) and (10) has a unique adjustment path for given initial capital stock, a saddle point, only if

$$
\frac{\partial \dot{c}}{\partial k}=\frac{c}{\sigma}\left[G_{k k}+G_{n k} \frac{\partial \tilde{n}}{\partial k}\right]<0 .
$$

We consider the system only in the steady state. Noting (5), (10) and the right-hand equation in (9), we obtain the steady-state conditions as follows:

$$
\begin{aligned}
& G(n, k)+h / 2-c-\tau(1 / 2-n)=0, \quad G_{k}(n, k)=\rho, \\
& \theta(1-a / 2)^{1-\sigma} n^{-\sigma}+\lambda\left[G_{n}(n, k)+\tau\right]=0,
\end{aligned}
$$

\footnotetext{
${ }^{3}$ This property of the endogenous-fertility models is explained e.g. in Palivos (1995).
} 
where $c, n$ and $k$ are endogenous and $\tau$ and $h$ exogenous variables. The comparative statics of the system (12) (see the Appendix) then gives

$$
n=N(\tau, h, a), \quad \partial N / \partial \tau>0, \quad \partial N / \partial h>0 .
$$

Hence, given the conscription rate $a$, a greater degree of discrimination for women (a higher $\tau$ and a higher $h$ ) increases the proportion of women in the production of children.

\section{The government}

The government can loose its power for two reasons. First, the elections are arranged from time to time and, to get re-elected, the government has to satisfy the needs of the households. Second, due to political instability, the government always faces the risk of a coup, a conflict, or a civil war, which removes it from power. Therefore, the government needs an army. With internal instability, the military must be proportional to population. ${ }^{4}$ For these reasons, the government's target function is a combination of the utility function of the representative household and the size of the military. Although the proportion $a$ of soldiers can be significant out of young men, their proportion out of all men is so small that in can be ignored. Hence, total male labor $L / 2$ can still be an input in the production function (1).

We specify the government's utility as the private utility (6) extended by the population share of the military, an $/ 2$ :

$$
W=\int_{0}^{\infty} \frac{1}{1-\sigma}\left\{c^{1-\sigma}+\theta\left[\left(1-\frac{a}{2}\right) n\right]^{1-\sigma}+\psi\left(\frac{a}{2} n\right)^{1-\sigma}-1\right\} e^{-\rho t} d t
$$

where the constant $\psi>0$ represents the risk of internal conflicts. Private and government utilities, (6) and (14), would coincide for $\psi=0$.

Because the fines on female labor are distributed among the men, we obtain $\tau(1-b) L / 2=h L / 2$ or $h / 2=(1-b) \tau / 2=(1 / 2-n) \tau$. Inserting this into the equation (5) yields the accumulation of the capital-labor ratio $k$ as

$$
\dot{k}=G(n, k)-c .
$$

\footnotetext{
${ }^{4}$ We assume that the government needs its army for internal rather than for external security. The proper deterrent against internal conflicts (i.e., banditry, riots, a civil war, etc.) is the size of the military relative to population, an $/ 2$, while that against intrusion from abroad is the absolute size of the military.
} 
The government decides what proportion $a$ of young men is taken in the army. Given (13), the government is able to control $n$ by discrimination. Hence, the government maximizes its utility (14) by choosing the size of military, $a$, the rate of population growth, $n$, and consumption per capita $c$, subject to capital accumulation (15). Omitting constants, we obtain the Hamiltonian corresponding to this problem as follows:

$$
H^{G}=\frac{1}{1-\sigma}\left[c^{1-\sigma}+\theta\left(1-\frac{a}{2}\right)^{1-\sigma} n^{1-\sigma}+\psi\left(a \frac{n}{2}\right)^{1-\sigma}\right]+\mu[G(n, k)-c],
$$

where the co-state variable $\mu$ evolves according to

$$
\dot{\mu}=\rho \mu-\partial H^{G} / \partial k=\left[\rho-G_{k}(n, k)\right] \mu .
$$

To simplify the analysis, we define the functions

$$
\begin{aligned}
& A(\theta, \psi) \doteq \max _{a}\left[\theta(1-a / 2)^{1-\sigma}+\psi(a / 2)^{1-\sigma}\right], \quad \partial A / \partial \theta<0, \quad \partial A / \partial \psi>0 \\
& a(\psi / \theta) \doteq \arg \max _{a} A(\theta, \psi), \quad a^{\prime}>0 .
\end{aligned}
$$

In other words, higher risk of conflicts (i.e., a higher $\psi$ ) increases, but greater weight for young people (i.e., a higher $\theta$ ) decreases the rate of constription, $a$. The Hamiltonian (16) takes the form

$$
H^{G}=(1-\sigma)^{-1}\left(c^{1-\sigma}+A n^{1-\sigma}\right)+\mu[G(n, k)-c] .
$$

The first-order conditions for the government's maximization are given by

$$
c^{-\sigma}=\mu, \quad \partial H^{G} / \partial n=A n^{-\sigma}+\mu G_{n}(n, k)=0 .
$$

Given (20), we can replace $\mu$ by $c$ as the co-state variable and transform the equation (8) into

$$
\dot{c} / c=-(1 / \sigma) \dot{\mu} / \mu=(1 / \sigma)\left[G_{k}(n, k)-\rho\right] .
$$

From (4) and (20) it follows that

$$
\frac{\partial^{2} H^{G}}{\partial n \partial k}=c^{-\sigma} G_{n k}<0, \quad \frac{\partial^{2} H^{G}}{\partial n \partial c}=-G_{n} \sigma c^{-\sigma-1}=A n^{-\sigma} \frac{\sigma}{c}>0 .
$$


Given these inequalities and the second-order condition $\partial^{2} H / \partial n^{2}<0$, the comparative statics of the right-hand equation in (9) yields

$$
n=\hat{n}(k, c), \quad \frac{\partial \hat{n}}{\partial k}=-\frac{\partial^{2} H}{\partial n \partial k} / \frac{\partial^{2} H}{\partial n^{2}}<0, \quad \frac{\partial \hat{n}}{\partial c}=-\frac{\partial^{2} H}{\partial n \partial c} / \frac{\partial^{2} H}{\partial n^{2}}>0 .
$$

Noting (11), we obtain that the system (5) and (10) has a unique adjustment path for given initial capital stock, a saddle point, only if

$$
\frac{\partial \dot{c}}{\partial k}=\frac{c}{\sigma}\left[G_{k k}+G_{n k} \frac{\partial \hat{n}}{\partial k}\right]<0
$$

We consider the system only in the steady state. Noting (15), (21) and (20), we obtain the steady-state conditions as $c=G(n, k)$ and

$$
G_{k}(n, k)=\rho, \quad A n^{-\sigma} G(n, k)^{\sigma}+G_{n}(n, k)=0 .
$$

In the system (23), variables $n$ and $k$ are endogenous and $A$ is exogenous. By the comparative statics of this system (see the Appendix), we obtain $d n / d A>0$. This and (18) yield the following result:

Proposition. (i) Higher risk of conflicts (i.e., an increase in $\psi$ ) increases the discrimination of women in the labor force, the fertility rate $n$ and the size of the military, an/2.

(ii) A greater weight for young people in the families (i.e., an increase in $\theta$ ) decreases the population growth rate $n$.

These results can be explained as follows. When the government have incentives to expand the military, it conscripts more young men. The less young people are needed in families, the higher can the conscription rate a. Because there is, however, an economic limit for conscription - the lack of young men in the end harms families - the government must ensure the long-run supply of young men. Discrimination imposed by the government compels some of the women change the labor force into child-rearing. This increases fertility and the average number of young men in the long run.

Assume that there is an increase in the risk of conflict (i.e., $\psi$ increases). To hedge against this risk the government increases the conscription rate $a$. On the other hand, the government faces the risk of not being re-elected by 
the dissatisfied citizens, who had to turn their members to the army. Fortunately, increased labor market discrimination provides a way out of the dilemma. Women's retreat from the labor force naturally decreases household's income and consumption but new family members compensate this. In the new equilibrium, the increased conscription rate is outweighed by a higher number of young people. Hence, if the government can induce an increased population growth rate, its need to increase the conscription rate less than in the case of no population growth.

\section{Some empirical evidence}

The model above predicts that countries experiencing high risks of conflicts generate high population growth rates. However, because we abandoned the time lag from the birth to the age of conscription, this prediction must now be re-interpreted. In the real world, it takes almost 20 years for newborns to growth up to potential soldiers. On the other hand, it is well known that recently experienced risks affect evaluations on future risks. Hence, we may well assume that if the current risk of conflicts is high, a forward-looking government has every incentive to promote fertility. High military spending then reveals that the government's expectations on future risks are high.

On the basis of the above discussion, we use the military share (MILPERS ) - i.e. the proportion of military personnel out of total population - as the proxy of political risks in future. In order to test the prediction of the model, want to regress the annual population growth rate (POPGR) against the military share. We collect data for years 1989-1999 for 72 low and middle income countries with population larger than one million from World Bank (2002). ${ }^{5}$ The data availability dictates the years. We estimate

$$
P O P G R=\alpha+\beta \cdot M I L P E R S+\gamma \cdot X+\varepsilon,
$$

in which $X$ is the set of variables to be controlled for. To get started, we first forget $X$ and derive the ordinary least square estimate $\beta=0.145$ with the $t$-value 3.42 which is statistically significant at $0.1 \%$ level and of expected sign. Figure 1 depicts the association in the data.

\footnotetext{
${ }^{5}$ For definition of low and middle income countries, see World Bank (2002). We excluded Rwanda and China and Jordan 1989 (an outlier in military).
} 


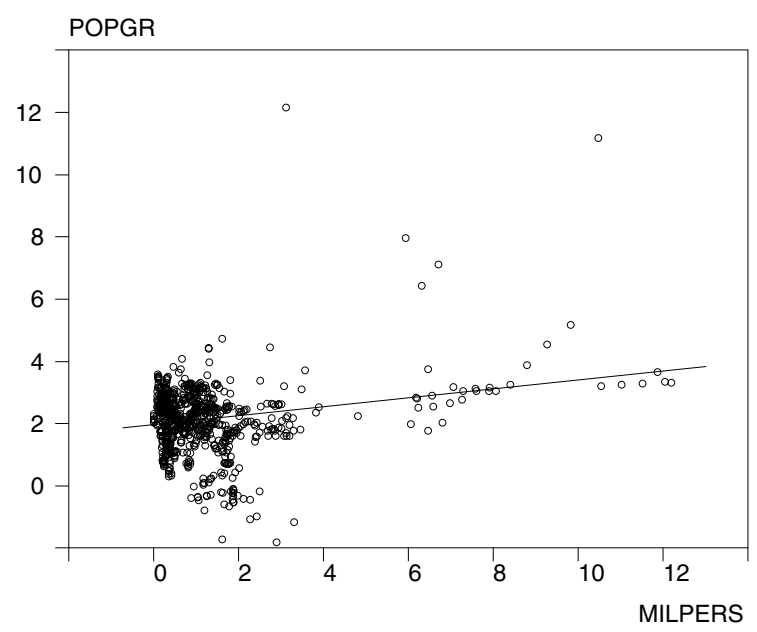

Figure 1: The population growth rate and the share of the military.

The association, however, may be spurious and may merely reflect the presence of a "common explanatory variable". To see this, note that the variable $P O P G R$ is strongly autocorrelated with lag of one generation. If twenty years ago there has been an exceptionally large cohort of newborns, a lot of people are now both in the age of making children and going to military. Therefore, the number of children and the share of military swell together even if no causality runs from MILPERS to POPGR. To eliminate this cohort effect we take the population growth rate lagged with twenty years $\left(P O P G R_{-20}\right)$ as an independent variable to the model.

Several other explanations for population growth has been suggested. ${ }^{6}$ Barro and Sala-i-Martin (1995) argue that an explanation for population growth is provided in education. Some others insist that trade with rich countries has induced demographic changes in poor countries. ${ }^{7}$ Brander and Taylor (1998), and Maxwell and Reuveny (2000) study the Malthusian argument that fixed natural resources and population density are the main determinants of population growth. They suggest that population density

\footnotetext{
${ }^{6}$ Lehmijoki (2003) provides a review of determinants for population growth.

${ }^{7}$ Caldwell (1982) claims that import of western values together with goods and services tends to decrease population growth. Bongaarts and Watkins (1996) also emphasize the role of diffusion of information. An alternative explanation for the role of trade was provided by Haaparanta (2004) who argued that, in some cases, trade opening makes people in a poor country to specialize to agriculture and move back to countryside where population grows faster so that trade opening increases population growth.
} 


\begin{tabular}{|c|c|c|c|}
\hline "Model & $\begin{array}{l}\text { OLS } \\
1\end{array}$ & $\begin{array}{l}\text { FEM } \\
2\end{array}$ & $\begin{array}{l}\text { PERIOD } \\
3\end{array}$ \\
\hline MILPERS & $\begin{array}{l}24.1 \\
(5.107)\end{array}$ & $\begin{array}{l}16.3 \\
(3.746)\end{array}$ & $\begin{array}{l}10.9 \\
(2.47)\end{array}$ \\
\hline$P O P G R_{-20}$ & $\begin{array}{l}43.3 \\
(9.177)\end{array}$ & $\begin{array}{l}-40.9 \\
(-6.424)\end{array}$ & $\begin{array}{l}-39.4 \\
(-6.26)\end{array}$ \\
\hline LITERACY & $\begin{array}{l}-2.1 \\
(-9.26)\end{array}$ & $\begin{array}{l}-1.6 \\
(-2.948)\end{array}$ & $\begin{array}{l}-0.3 \\
(-0.49)\end{array}$ \\
\hline$T R A D E$ & $\begin{array}{l}0.3 \\
(3.75)\end{array}$ & $\begin{array}{l}-0.2 \\
(-1.077)\end{array}$ & $\begin{array}{l}0.1 \\
(0.42)\end{array}$ \\
\hline DENSITY & $\begin{array}{l}-0.1 \\
(-6.15)\end{array}$ & $\begin{array}{l}-0.4 \\
(-1.815)\end{array}$ & $\begin{array}{l}0.2 \\
(0.57)\end{array}$ \\
\hline$E A P$ & $\begin{array}{l}68 \\
(7.06)\end{array}$ & & \\
\hline$S A S$ & $\begin{array}{l}60 \\
(4.95)\end{array}$ & & \\
\hline$L A C$ & $\begin{array}{l}83 \\
(8.78)\end{array}$ & & \\
\hline$S S A$ & $\begin{array}{l}90 \\
(7.21)\end{array}$ & & \\
\hline$R^{2}$ & .55 & 0.77 & 0.78 \\
\hline
\end{tabular}

Table 1: Dependent variable population growth (POPGR). In OLS, heteroscedasticity corrected standard errors are used. All coefficients multiplied by 100 . $t$-values given in parenthesis. 
(or resource scarcity) sets limit to population growth. To control for all these variables we take the literacy rate of total population (LITERACY), the GDP-share of international trade (TRADE), and the population density (DENSITY) as right hand side variables into the regression. We also introduce four regional dummies namely East Asian and Pacific $(E A P)$, South Asia $(S A S)$, Latin America $(L A C)$, and Sub-Saharan Africa $(S S A)$. The OLS results are given in regression 2 in Table 1.

Regression 1 shows that the association between POPGR and MILPERS well preserves the scrutinity of several additional variables and areal dummies and the estimate for $\beta$ increases. The following two columns in Table 1 report the fixed-effect model with fixed effects allowed, and the two-way model with both period and fixed effects allowed. ${ }^{8}$ In both these models the coefficient for MILPERS is relatively stable. ${ }^{9}$ Hence, even if Figure 1 shows that the positive association between the military share and population growth is not especially prominent, this association is robust. From 1989 to 1999 population growth rate decreased from $2.21 \%$ to $1.88 \%$ in the sample; regression 3 in Table 1 then says that the decrease in the military share, which was 0.33 percentage units during the period in question, was responsible for about $10 \%$ of the occurred decrease in population growth rate. The population in the countries of the sample increase from 1002 million in 1950 to 3044 million in 2000. If we assume that the results above hold for the entire period $1950-2000$, then political instability was responsible for the increase in population by 2.2 million people in the sample.

Note, however, that even if we eliminated the cohort effect, the possibility of reversed causality is still present. It is possible that the causality runs from the population growth rate to the military share. As usually, complete elimination of the problem by instrumental estimation is difficult but some preliminary contemplations are possible. Brander and Taylor (1998), and Maxwell and Reuveny (2000) claim that continuous population growth nec-

\footnotetext{
${ }^{8}$ The test results 462 for the Lagrange multiplier and 120 for the Hausman test favor FEM over OLS and the random effect model.

${ }^{9}$ Interesting feature in Table 1 is that if country-specific constants are allowed the coefficient for POPGR -20 switches from significantly positive to significantly negative. The explanation is that population growth is (autocorrelated and) trended. The sample average of population growth increased until 1981 and then decreased. Allowing countryspecific constants reveals the negative correlation between trends.
} 
essarily leads to scarcity of natural resources such as arable land which may lead to conflicts about access to these resources. ${ }^{10}$ Hence, we take population density as a measure of the scarcity of land but we find that the correlation between DENSITY and MILPERS is -0.15 which is in wrong direction: the greater the scarcity, the lower the revealed risk for conflict. It is also possible that a fast population growth increases unemployment among young men, and that idle, frustrated young men are potential rebels. We have occasional data for unemployment of young men for 26 countries, but its correlation with MILPERS (the revealed measure of risk) is only 0.06 which is in the expected direction but small. Hence, we find no apparent evidence for reversed causality even if this possibility cannot be completely excluded.

The model also suggests that governments facing risks for internal conflicts, discriminate working women to compel them to change into childcaring. Therefore, we test whether the female participation rate (FEMLAB) is associated with MILPERS by running

$$
F E M L A B=\zeta+\eta \cdot M I L P E R S+\varepsilon,
$$

to find $\eta=-2.54$ which is big and significant ( $t$-value is -12.38$)$. Actually, MILPERS explains $22 \%$ of female discrimination in the sample. This result is depicted in Figure 2.

The astonishing fact in Figure 2 is that this intermediate result seems to stronger than the main result, namely the positive association between the military share and population growth in Figure 1. One explanation is that during the years for which the data is available the weight for children in household preferences already was relatively low (i.e., $\theta$ was low, cf. proposition $(i i))$. Hence, even if governments still were able to push women out of the labor force, they were no more so successful in achieving their target of population growth. If this were the case, then the the demographic effects of political instability may earlier have been stronger, i.e., the multiplier $\beta$ in (24) was possible larger.

\footnotetext{
${ }^{10}$ Quite the opposite view is adobted by the proponents of the resource-curse argument which says that abundant natural resources, such as diamonds, lead to civil conflicts. For a review, see Olsson 2004.
} 


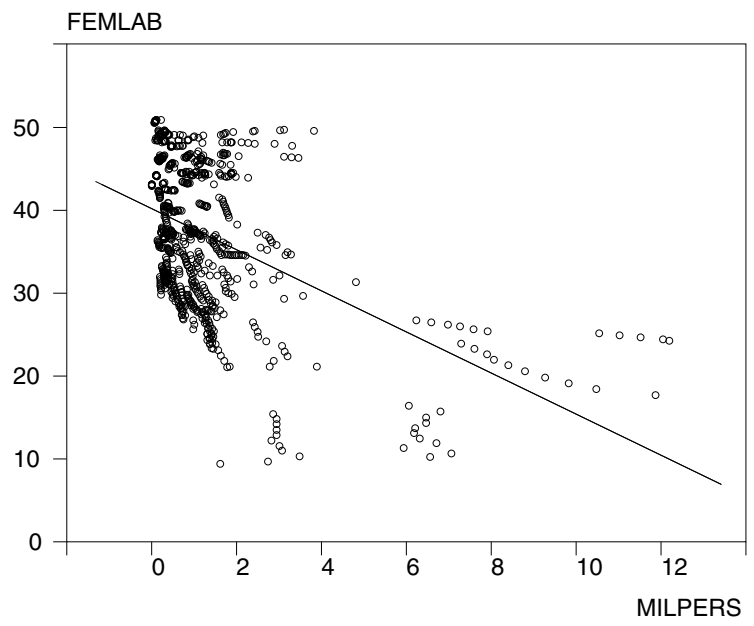

Figure 2: The female participation rate and the share of the military.

\section{Conclusions}

The existence of the military is necessary for any society, but its extent depends on political instability. Building up the military reduces the risk of conflicts, but also decreases the popularity of the government. Because there is a trade-off between these two, there is an optimal rate of conscription for a government. Consequently, the government can maintain a big military only through keeping up high fertility. For a given rate of conscription, the number of soldiers is the larger, the larger the cohort of young men. The government promotes fertility by discriminating women in the labor market in order to compel them to child-rearing. Hence, the size of the military, the discrimination of women and the fertility rate are all positively associated.

To consider this assertion, we construct a theoretical model as follows. Households are family dynasties, which obtain utility from consumption per capita and the number of children, but sending children to the army deceases its welfare. Goods are produced from capital, male labor and female labor according to neoclassical technology with constant returns to scale. Some female labor is allocated in child-rearing to produce young family members.

The government sets the conscription rate at which young men are taken in the military. It also controls fertility by discriminating women in the labor force. Because there is an equilibrium conscription rate, the government can build up the military only through higher fertility in the long run. We test 
this assertion also empirically. The results reveal a robust positive association between the proportion of military personnel out of population, the fertility rate and the discrimination of women in the developing countries.

The model in this paper is the first attempt to explain the interdependence of political economy and population growth in the case the government has to maintain the army to control for political instability in the country. It could be extended and made more concrete as follows:

(i) The public sector could be modelled entirely, e.g. through the introduction of public services (e.g. schooling) as well as specific taxes on consumption, capital and male and female labor. It would be instructive to see whether the governments would still discriminate women even if more policy instruments are available.

(ii) The economy could be opened such that there are two sectors producing exported and imported goods. One of these sectors could use male labor and the other female labor more intensively. This framework could reveal something about the relationship of international trade, gender discrimination, the military and fertility.

(iii) There exists a labor-intensive natural-resource sector (e.g. diamonds) in the economy. ${ }^{11}$ This approach could explain how the discovery of new resources affects gender discrimination, the military and fertility.

(iv) The military capacity could crowd-out labor from the productive sector.

These tasks are left for future research.

\footnotetext{
${ }^{11}$ Cf. Olsson (2004).
} 


\section{Appendix}

Section 2:

The uniqueness of the path of the system requires that the Hamiltonian (7) must be strictly concave in $(n, k)$ when $c$ (and consequently $\lambda=c^{-\sigma}$ ) is kept constant. Given this and $\lambda=c^{-\sigma}$, we obtain

$$
\begin{aligned}
0 & <c^{2 \sigma}\left|\begin{array}{cc}
\frac{\partial^{2} H}{\partial n^{2}} & \frac{\partial^{2} H}{\partial n \partial k} \\
\frac{\partial^{2} H}{\partial n \partial k} & \frac{\partial^{2} H}{\partial k^{2}}
\end{array}\right|=c^{2 \sigma}\left|\begin{array}{cc}
\lambda G_{n n}-\sigma \theta(1-a / 2)^{1-\sigma} n^{-\sigma} & \lambda G_{n k} \\
\lambda G_{n k} & \lambda G_{k k}
\end{array}\right| \\
& =c^{2 \sigma}\left[\lambda^{2}\left(G_{n n} G_{k k}-G_{n k}^{2}\right)-\sigma \theta(1-a / 2)^{1-\sigma} n^{-\sigma-1} \lambda G_{k k}\right] \\
& =G_{n n} G_{k k}-G_{n k}^{2}-\sigma \theta(1-a / 2)^{1-\sigma} n^{-\sigma-1} c^{\sigma} G_{k k} .
\end{aligned}
$$

Differentiating the system (12) totally, we obtain

$$
\begin{aligned}
& \left(\begin{array}{ccc}
G_{k} & G_{n}+\tau & -1 \\
G_{k k} & G_{n k} & 0 \\
G_{n k} & G_{n n}-\sigma \theta(1-a / 2)^{1-\sigma} c^{\sigma} n^{-\sigma-1} & \sigma \theta(1-a / 2)^{1-\sigma} c^{\sigma-1} n^{-\sigma}
\end{array}\right)\left(\begin{array}{l}
d k \\
d n \\
d c
\end{array}\right) \\
& +\left(\begin{array}{cc}
n-1 / 2 & 1 / 2 \\
0 & 0 \\
0 & 0
\end{array}\right)\left(\begin{array}{l}
d \tau \\
d h
\end{array}\right)=0
\end{aligned}
$$

Noting (26), the Jacobian of this system is given by

$$
\begin{aligned}
\mathcal{J}= & \left|\begin{array}{ccc}
G_{k} & G_{n}+\tau & -1 \\
G_{k k} & G_{n k} & 0 \\
G_{n k} & G_{n n}-\sigma \theta(1-a / 2)^{1-\sigma} c^{\sigma} n^{-\sigma-1} & \sigma \theta(1-a / 2)^{1-\sigma} c^{\sigma-1} n^{-\sigma}
\end{array}\right| \\
= & \underbrace{(-1)^{1+3}(-1)}_{-1}\left|\begin{array}{cc}
G_{k k} & G_{n k} \\
G_{n k} & G_{n n}-\sigma \theta(1-a / 2)^{1-\sigma} c^{\sigma} n^{-\sigma-1}
\end{array}\right| \\
& +\underbrace{(-1)^{3+3}}_{+1} \sigma \theta(1-a / 2)^{1-\sigma} c^{\sigma-1} n^{-\sigma}\left|\begin{array}{cc}
G_{k} & G_{n}+\tau \\
G_{k k} & G_{n k}
\end{array}\right| \\
= & \underbrace{G_{n k}^{2}-G_{k k} G_{n n}+\sigma \theta(1-a / 2)^{1-\sigma} c^{\sigma} n^{-\sigma-1} G_{k k}}_{-} \\
& +\underbrace{\sigma \theta(1-a / 2)^{1-\sigma} c^{\sigma-1} n^{-\sigma}}_{+}[\underbrace{G_{k}}_{+} \underbrace{G_{n k}}_{-}-(\underbrace{G_{n}+\tau}_{-}-c / n) \underbrace{G_{k k}}_{-}]<0 .
\end{aligned}
$$

Furthermore, we obtain

$$
\frac{\partial n}{\partial \tau}=-\frac{1}{\mathcal{J}}\left|\begin{array}{ccc}
G_{k} & n-1 / 2 & -1 \\
G_{k k} & 0 & 0 \\
G_{n k} & 0 & \sigma \theta(1-a / 2)^{1-\sigma} c^{\sigma-1} n^{-\sigma}
\end{array}\right|
$$




$$
\begin{aligned}
& =-\frac{1}{\mathcal{J}}(-1)^{1+2}(n-1 / 2)\left|\begin{array}{cc}
G_{k k} & 0 \\
G_{n k} & \sigma \theta(1-a / 2)^{1-\sigma} c^{\sigma-1} n^{-\sigma}
\end{array}\right| \\
& =-(1 / \mathcal{J}) \underbrace{(1 / 2-n)}_{+} \underbrace{G_{k k}}_{-} \underbrace{\sigma \theta(1-a / 2)^{1-\sigma} c^{\sigma-1} n^{-\sigma}}_{+}<0, \\
\frac{\partial n}{\partial h} & =\left|\begin{array}{ccc}
G_{k} & 1 / 2 & -1 \\
G_{k k} & 0 & 0 \\
G_{n k} & 0 & \sigma \theta(1-a / 2)^{1-\sigma} c^{\sigma-1} n^{-\sigma}
\end{array}\right| \\
& =(1 / \mathcal{J}) \underbrace{(1 / 2)}_{+} \underbrace{G_{k k}}_{-} \underbrace{\sigma \theta(1-a / 2)^{1-\sigma} c^{\sigma-1} n^{-\sigma}}_{+}>0 .
\end{aligned}
$$

\section{Section 4:}

The uniqueness of the path of the system requires that the Hamiltonian (16) must be strictly concave in $(n, k)$ when $c$ (and consequently $\mu=c^{-\sigma}$ ) is kept constant. Given this and $\mu=c^{-\sigma}$, we obtain

$$
\begin{aligned}
0 & <c^{2 \sigma}\left|\begin{array}{cc}
\frac{\partial^{2} H^{G}}{\partial n^{2}} & \frac{\partial^{2} H^{G}}{\partial n \partial k} \\
\frac{\partial^{2} H^{G}}{\partial n \partial k} & \frac{\partial^{2} H^{G}}{\partial k^{2}}
\end{array}\right|=c^{2 \sigma}\left|\begin{array}{cc}
\mu G_{n n}-\sigma A n^{-\sigma-1} & \mu G_{n k} \\
\mu G_{n k} & \mu G_{k k}
\end{array}\right| \\
& =c^{2 \sigma}\left[\mu^{2}\left(G_{n n} G_{k k}-G_{n k}^{2}\right)-\sigma A n^{-\sigma-1} \lambda G_{k k}\right] \\
& =G_{n n} G_{k k}-G_{n k}^{2}-\sigma A n^{-\sigma-1} c^{\sigma} G_{k k} .
\end{aligned}
$$

Differentiating the system (23) totally, we obtain

$$
\begin{gathered}
\left(\begin{array}{cc}
G_{k k} & G_{n k} \\
\sigma A n^{-\sigma} G^{\sigma-1} G_{k}+G_{n k} & \sigma A n^{-\sigma} G^{\sigma-1}\left(G_{n}-G / n\right)+G_{n n}
\end{array}\right)\left(\begin{array}{l}
d k \\
d n
\end{array}\right) \\
+\left(\begin{array}{c}
0 \\
n^{-\sigma} G^{\sigma}
\end{array}\right) d A=0 .
\end{gathered}
$$

Given (4) and (18), we obtain Jacobian of this system as

$$
\begin{aligned}
J & =\left|\begin{array}{cc}
G_{k k} & G_{n k} \\
\sigma A n^{-\sigma} G^{\sigma-1} G_{k}+G_{n k} & \sigma A n^{-\sigma} G^{\sigma-1}\left(G_{n}-G / n\right)+G_{n n}
\end{array}\right| \\
& =\left|\begin{array}{cc}
G_{k k} & G_{n k} \\
G_{n k} & G_{n n}-\sigma A n^{-\sigma-1} G^{\sigma}
\end{array}\right|+\left|\begin{array}{cc}
G_{k k} & G_{n k} \\
\sigma A n^{-\sigma} G^{\sigma-1} G_{k} & \sigma A n^{-\sigma} G^{\sigma-1} G_{n}
\end{array}\right| \\
& =\left|\begin{array}{ccc}
G_{k k} & G_{n k} & \left|\begin{array}{cc}
G_{k k} & G_{n k} \\
G_{n k} & G_{n n}-\sigma A n^{-\sigma-1} c^{\sigma}
\end{array}\right|+\sigma A n^{-\sigma} G^{\sigma-1}
\end{array}\right| \\
& =\underbrace{G_{k k} G_{n n}-G_{n k}^{2}-\sigma A n^{-\sigma-1} c^{\sigma} G_{k k}}_{+}+\underbrace{\sigma A n^{-\sigma} G^{\sigma-1}}_{+}[\underbrace{G_{n}}_{-} \underbrace{G_{k k}}_{-}-\underbrace{G_{k}}_{+} \underbrace{G_{n k}}_{-}]>0 .
\end{aligned}
$$


Given this, (4) and (18), we obtain

$$
\frac{\partial n}{\partial A}=-\frac{1}{J}\left|\begin{array}{cc}
G_{k k} & 0 \\
\sigma A n^{-\sigma} G^{\sigma-1} G_{k}+G_{n k} & n^{-\sigma} G^{\sigma}
\end{array}\right|=-\frac{1}{J} G_{k k} n^{-\sigma} G^{\sigma}>0 .
$$

\section{References:}

Azam, J.-P. (1995): "How to Pay the Peace? A Theoretical Framework with References to African Countries." Public Choice 83, 173-184.

Azam, J.-P. (2002): "Looting and Conflicts between Ethnoregional Groups." The Journal of Conflict Resolution 46, 131-153.

Azam, J.-P. (2003): "Civil War and Social Contract." Public Choice 115: 455-475.

Barro, R. J. and Sala-i-Martin, X. (1995): Economic Growth. McGraw-Hill. New York.

Becker, G. S. (1981): A Treatise on the Family. Gambridge, Massachusetts: Harvard University Press.

Bongaarts, J. and Cotts Watkins, S, (1996): "Social Interactions and Contemporary Fertility Transitions." Population and Development Review 22, 639-682.

Brander, J. and Taylor, M.S. (1998): "The Simple Economics of Easter Island: A Ricardo-Malthus Model of Renewable Resource Use." American Economic Review 88: 119-138.

Caldwell, J. C. (1982): Theory of Fertility Decline. London: Academic Press. Collier, P. and Hoeffler, A. (1998): "On Economic Causes of Civil Wars." Oxford Economic Papers 50: 563-573.

Easterly, W. and Levine, R. (1997): "Africas Growth Tragedy: Policies and Ethnic Division." Quarterly Journal of Economics 4: 1203-1250.

Eriksson, M. and Wallensteen, P. (2004): "Armed Conflicts." Journal of Peace Research 41: 625-636.

Grossman, H.I. (1991): "A General Equilibrium Model of Insurrections." American Economic Review 81: 912-921. 
Grossman, H.I. (1995): "Insurrections." (Hartley, K. and T. Sandler (eds), Handbook of Defence Economics, Vol I, Elsevier Science B.V., Amsterdam.

Grossman, H.I. and Kim, M. (1995): "Swords or Plowshares? A Theory of the Security of Claims to Property." Journal of Political Economy 103: 1275-1288.

Haaparanta, P. (2004): "International Trade, Resource Curse and Demographic Transition." HECER Discussion Paper No 11.

Lehmijoki, U. (2003): Demographic Transition and Economic Growth. PhD Thesis. Yliopistopaino. Helsinki.

Maxwell, J. and Reuveny, R. (2000): "Resource Scarcity and Conflict in Developing Countries." Journal of Peace Research 37: 301-322.

Olsson, O. (2004): "Conflict Diamonds." A Paper Presented in the Ninth Conference of Dynamics, Economic Growth, and International Trade (DEGIT), Reykjavik, Iceland, June 11-12, 2004. Forthcoming in Journal of Development Economics.

Palivos, T. (1995): "Endogenous Fertility, Multiple Growth Paths, and Economic Convergence." Journal of Economic Dynamics and Control 19: 14891510 .

Razin, A. and Ben-Zion, U. (1975): "An Intergenerational Model of Population Growth." American Economic Review 65: 923-933.

Stockholm International Peace Research Institute (SIPRI) (2004): SIPRI Yearbook 2004. Stockholm.

United Nations (2003): World Population prospects: The 2002 version. CDdiscette. New York.

World Bank (2002): World Development Indicators 2002. Online Version. 